\title{
Provoking Mobile Payment Actual Usage Behaviour in Middle East
}

\author{
A.R.M. Musallam ${ }^{1}$, P.S. JosephNg ${ }^{2}$, H.C. Eaw $^{3}$ \\ ${ }^{1}$ Graduate Business School, ${ }^{2}$ Institute of Computer Science \& Digital Innovation, ${ }^{3}$ Faculty of Business and Management \\ UCSI University \\ UCSI Heights, 1, Jalan Puncak Menara Gading, Taman Connaught, 56000 Cheras, Wilayah Persekutuan Kuala Lumpur, \\ Malaysia \\ [1001851246; josephng; eawhc] @ucsiuniversity.edu.my
}

\begin{abstract}
.
Financial Payment has evolved into mobile payment for easy access and convenience. Despite the benefits of mobile payment, the adoption rate is unsatisfactory worldwide. Therefore, understanding the customer's adoption intention factors is essential for both researchers and practitioners. This study examines mobile payment intention and actual use by adapting the integrated framework, which combines the Mobile Technology Acceptance Model and the Theory of Planned Behaviour with additional new constructs found to be related. The new model consists of 12 variables moderated by the individual's experience and is examined via a structured PLS equation mixed-mode methodology. Knowing mobile payment influence will shape the industry strategic decision and socially contribute to transforming society into a cashless society. This paper provides an opportunity to prove the relationship between technology variables and human behaviour concerning mobile payment adoption. In contrast, this study novelty adopted an integrated model that combines MTAM with the TPB.
\end{abstract}

Keywords: Mobile Payment; Payments Adoption; Mobil Technology Acceptance Model; Revised Mobile Payment Acceptance Model, Digitization of financial services, Theory of planned behavior 


\section{INTRODUCTION}

Mobile Payment is an innovative technology, and it transformed the way the banking sector is functioning. It enables individuals to transact and interact with banking institutions without being present physically in any branch or using automated teller machines (ATM). The payment by mobile or defined mobile payment is performing a payment, initiating, authorizing payment by using a mobile device. Mobile Payment offers convenience, effectiveness and cost-saving (Merhi, Hone, Tarhini, \& Ameen, 2020). The global payment trend has switched to non-cash methods, and online payment becomes one of the most popular and widespread.

In the United States, $89 \%$ of consumers pay in cash using a credit card or debit card; only 7.7 prefer to use mobile payment instead (Simon-kucher \& Partners, 2018).

The impact of the worldwide pandemic COVID-19 directed the adoption of any alternative payment method other than cash to overcome the need for physical contact. The lately collected information reported rapid and drastic habit change (Flavian et al., 2020), forcing the research toward payment mechanisms that promote contactless. This information forms a valid and feasible force to understand the factors that provoke mobile payment adoption and actual use as the world moves toward a cashless society.

In principle, to use mobile payment services, the user must first open an account to link the payment instrument (Card, Wallet) to his bank or financial institution. Then user only will enable the user to send money to the merchant/others or receive. On the other side, the merchant/individual who requests payment or accepts mobile payment must also exchange their payment information with the financial institution or bank. Then only will be able to receive the fund while providing consistent payment services from the various financial services. Therefore the payment request information which is received from the consumer is sent to the acquirer securely. The acquirer who has a direct relationship with the merchant forwards the payment information to the relevant financial institution so that payment can be completed. The whole cycle of this data flow, starting from the mobile user device and the follower series of processes, is called a mobile payment service (Kang, 2018).

The mobile payment service can be using the existing payment services provided by the financial institution and bank or middleman/through IT companies. However, the payment has to be linked to other third party systems to be completed in both cases. Indeed, the traditional payment services utilize IT infrastructure/ technologies similar to the Fintech payment services, it has some limitations and challenges. For example, suppose a mobile payment uses the existing traditional payment system and needs merchants in different financial institutions. In that case, a different payment handshake method must be used for each financial institution, even when they use the same service. Additionally, the traditional payment systems and platforms that provide the mobile payment service were not explicitly created for payment and not specialized for user convenience (Kang, 2018).

The mobile payment service involves different parties, starting from the mobile user device crossing the financial institutions' Issuer and acquirer systems, network provider and merchant systems. This will raise a security issue and will require proper and mutual authentication in place. The absence of such requirements can cause critical financial damage to the institutions, consumer, merchant and the whole payment system. For example, a middleman attack or malicious attack that changes the payment information can cause to deliver false payment details that can redirect the payment. Such a case can cause money debited from the user account but not received in the merchant or the desired beneficiary account. The customer got charged the service/product cost but did not receive the services/ product as the merchant did not receive the money (Kang, 2018).

The mobile payment service links and integrates with a variety of systems and apps. As a result, different policies and procedures are used to govern transaction flow in these systems, which can compromise end-user convenience and make it more difficult to access the application if high-security requirements are used. Nevertheless, security factors are background areas as customers will not see or experience directly. However, once security incidents happened, end-user trust in the system will be severely impacted (Kang, 2018).

To Sum up, a reasonable and viable force has emerged to understand better the factors that drive mobile payment acceptance and usage as the world moves toward a cashless society. To that end, the Mobile Technology Acceptance Model (MTAM) was used to create the base framework for this research. This model has been used in previous studies where the subject matter is mobile, or mobile 
services/apps are the focus. Besides, incorporating the Theory of Planned Behaviour (TPB) with additional constructs found to be related to analyse the practical use of mobile payments from the human behaviour perspective. The research would expand these models and analyse mobile payment intention and actual usage behaviour with the additional variable from other dimensions by integrating these two profoundly. The new revised model, named "Mobile Payment Technology Acceptance Model and Behaviour (MPTAMB)", also suggested the moderation of experience with mobile payments issues.

\section{LITERATURE REVIEW}

\subsection{Mobile Payment}

As an emerging technology with tremendous potential, Mobile Payment is now commonly used for purchasing movie tickets, paying for transportation, and many other items. In 2018, 938.2 million people used mobile payments around the world. China, India, and the United States account for more than two-thirds of the population. However, it has not been generally accepted in Western societies for many factors that affect mobile Payment ( Flavian, et al., 2020).

Mobile Payment is a revolutionary form of financial transaction that offers convenience and interactivity (Mouakket, 2020). The term "mobile payment" refers to using an electronic channel using mobile devices to pay for bills, goods, and services (Odoom \& Kosiba, 2020). Also, mobile payment was described as "the use of mobile devices to initiate, approve, and confirm the exchange of financial value in trade for any payment for goods and services" (Kumar, et al., 2020; Flavian, et al., 2020). "Mobile Payment" refers to a form of value transfer that works similarly to other payment methods but relies on advanced mobile innovative technologies and features. It is a representation/symbolization of a customer's financial credentials. While it is still a new tool, the international payment industry sees mobile phones as a good instrument for payment transactions (Dimitriadis, et al., 2018).

Mobile Payment extends access to financial services by using information and communication technologies and banks and non-bank retail networks. Specifically for customers who cannot be served conveniently or profitably by conventional physical-based locations. Today, creative and technologybased businesses thrive on easy, convenient, and ubiquitous mobile payment systems and rely on mobile technology (Kumar, et al., 2020). As a result, more businesses are shifting their payment strategies to the internet and mobile commerce (Kumar, et al., 2020). Several key advantages of mobile payment over traditional payment systems have been discussed in the literature, including their quietness and immediacy, which enable customers to use it from anywhere in the world at any time (Odoom \& Kosiba 2020; Mouakket 2020 ; Flavian, et al. 2020). In emerging economies, the current situation is favorable for growth, and mobile payment is continuing. Different factors remain challenges and obstacles. The Lion's share is that the fraud attempts by unauthorized individuals with bad intentions known as "middlemen attacks" have increased (Odoom \& Kosiba, 2020). As a result, mobile payment consumers are more cautioned against such attacks and hesitate to share a pin, for example, in other than primary bank application or agent's mobile application.

\subsection{Types of Mobile Payment}

Mobile payment types are in five group categories (Kumar, et al., 2020). SMS-based Payment, Action bill payment, Mobile device network payment, Wireless Application Protocol (WAP), Application payments (APP), and Contactless payments (Tap and Go) are the different types of payments. However, Mobile payment systems are either done remotely (far-end) or locally (proximate payments) (near-end) (Kumar, et al. 2020; Flavian et al., 2020).

Knowing and understanding what drives the consumer to choose a particular payment instrument and how different payment strategies are perceived helps financial service providers respond to changing customer expectations. Moreover, they should design their products and marketing campaigns to the needs of their current or future customers in order to gain customer loyalty and base (Semerikova, 2020). 


\subsection{Why people accept or resist mobile payment?}

Kothari (2018) argued that people do not use digital payment because lack of trust was at the top of the list. Some people are also hesitant to use the internet because of potential security threats. The thought of someone else having access to their bank account may be a deal-breaker for certain people. People in this category may have no prior experience with the internet and only a rudimentary understanding of how it operates. It is a big step into the unknown, mainly when no one can guide or explain it. The habit is the second reason; everyday life revolves around getting paid and paying in cash. It has been the standard way of doing business in many industries for a long time. There is simply no need to adapt for those who already transact in cash. They responsibly handle their cash and feel they are secure and in command at all times. The third explanation is that in countries like India, having every transaction monitored could lead to problems such as increased surveillance or higher taxes. Some customers prefer cash because it leaves no digital footprint. The fourth explanation is that cash is welcomed almost everywhere. Digital Payment, on the other hand, is not. The final explanation is friction; cash is a value transfer that occurs instantly. Despite recent advances, digital payments still require more steps than traditional cash transactions. Some consumers assume that money is genuine if they can count it hand. It is also a cultural problem. Because having a wallet full of cash notes, can demonstrate power and influence; but, when looking at the screen to check a balance, the result is not the same.

\subsection{Theoretical framework and hypotheses}

Mobile payment technology actual use is examined in this current study from two angles, from the technology adoption and the consumer behavior angle. The MTAM grounded from the TAM Model Davis et al. (1989, 1993) (Oertzen \& Odekerken-Schröder, 2019) will cover mobile payment as a technology from the adoption perspective. The Theory of Planned Behavior (TPB) of Ajzen (1991) examined consumer behavior (Jiang, Miao, Jalees, \& Zaman, 2019). Integrating these two profoundly theories with the additional variable from other dimensions addresses the shortfall of previous studies. Incorporating technology adoption and consumer behavior constructs will extend these models and examine mobile payment intention and actual use behavior to address the shortfall of previous studies. The moderation experience with mobile payment is also proposed in the new revised model and named "Mobile Payment Technology Acceptance Model and Behavior (MPTAMB)".

Mobile Technology Acceptance Model (MTAM)

It was developed to examine the smartphone Credit Card (SCC). SCC uses short-range wireless technology between two devices near each other with a maximum distance between 10-centimetre or fewer (Ooi \& Tan, 2016). Additional constructs added to the original TAM model to accommodate the mobile environment complexity. For the current study, MTAM was used as a base, and other variables added. Moreover, the shortfall of MTAM sorted by adding a new variable.

\section{The Theory of Planned Behavior}

The Theory of Reasoned Actioned (TRA) of Fishbone and Janzen 1975 was modified by Ajzen from 1985 to 1991 by adding the perceived behavioral control and called Theory of Planned Behavior (TPB) (Verma, et al., 2020). The involvement of the newly added construct in the TRA found very relevant to explain individual intention. According to previous studies, TPB and TAM are the most widely used theories to explain mobile services adoption and predict all kinds of human behaviors. There have been calls to duplicate and extend the TPB use due to divergent results and weak exploratory (Khoi, et al., 2018).

\subsection{Hypotheses Development}

Perceived value: - Customer will use the product or service to determine the expected value if the expected benefits are greater than its risk (Ryu, 2018). Therefore, perceived values are reflecting in meeting users' needs. The conceptualization of perceived value has been most widely accepted as "the consumer's overall assessment of the utility of a product based on perceptions of what is received and what is given" (Feng, et al., 2020). Thus, if a customer can use mobile payment services with the same 
success experienced in the physical environment, the perceived value increases (Lin, et al., 2020).

H1. Perceived value influence an individual's mobile payment intention use and ultimately affects the actual user behavior.

Digital social media people influence: - is a collection of online content of social interactions among users and allows them to co-create, find, share and evaluate forming an online information repository" (Hew, et al., 2016). Digital Social media influence is the impact consumers perceive from the people that particular behavior should or not perform (Trinh, et al., 2020). The rising of social media is a cornerstone of social commerce. Social media have redefined the organization's lifestyle and practices over the past decade (Hew, et al., 2016).

Digital social media people affect the customer's intention toward using mobile Payment (Trinh, et al., 2020). Therefore, other community members' social influence affects an individual's decision (Patten, et al., 2020). Additionally, the significant direct impact of social influence on intention use behavior is a finding in a recent study to examine mobile banking adoption in Bangladesh (Islam, et al., 2019).

H2. Digital social media people's thoughts influence an individual's mobile payment intention use and ultimately affects the actual user behavior.

Facilitation Conditions: - The facilitating conditions are the level of consumer believes in organization and infrastructure to support the use of the service (Gupta, et al., 2019). Therefore, consumer most likely uses the mobile payment system if they have support services and resources to assist (Gupta, et al., 2019).

Facilitating conditions includes the user's knowledge, ability and resources (Odoom \& Kosiba, 2020). It is worth noting that Odoom and Kosiba (2020) study focused on mobile money continuance intention among micro-enterprises with a sample of 584 micro-enterprises. The study adopted the unified theory of acceptance and use of technology (UTAUT). The study confirmed the relationship between facilitation condition and continuance intention with a p-value of less than 0.01 . This formulates the following hypotheses.

H3. Facilitation condition influence individual's mobile payment intention use and ultimately affects the actual user behavior.

Technical feasibilities: - Is referred to the consumer technical skill, technology savvy. Leong et al. (2021) informed that mobile services' technical constraints affect the user's attitude in using the service. Due to the sensitivity and privacy of the exchanged data in payments, mobile payment adds a new level of complexity (Leong, et al., 2021).

Mobile Payment introduces a new level of complexity, considering that the information's sensitivity and privacy affect the user from two angles (Leong, et al., 2021). One user might find it tedious and complicated due to the constraints of the features of mobile devices such as small screen, in screen typing, difficulty entering information by using the mobile device screen, and the perception of inadequate security protection. Therefore, if the mobile payment provider provides technical assistance, this will encourage the actual use of the service (Danyali, 2018).

H4. Consumer technical feasibilities influence an individual's mobile payment intention use and ultimately affects the actual user behavior.

Mobile Payment Perceived Trust: - Trust is essential and curtails, particularly when related to financial transactions, mainly when the transactions process via a wireless network (Cao, et al., 2018). The term trust in payment services means that the user has a certain confidence level in the service provider ability, integrity, and benevolence (Cao, et al., 2018). Therefore, building consumer trust leads to a long relationship with the consumer and continues using mobile Payment (Cao, et al., 2018).

In addition, the effect of perceived trust was previously measured on a quantitative study include an analysis of 1245 respondents, and it was found that perceived trust has a substantial impact on the intention to adopt mobile banking. This formulates the following hypotheses.

H5. Perceived trust influence an individual's mobile payment intention use and ultimately affects the actual user behavior.

Perceived Usefulness and Ease of Use: - perceived usefulness triggers an adequate response (attitude toward using), which forms the behavioral intention to use, and ultimately determines the actual behavior (Oertzen \& Odekerken-Schröder, 2019). Process Complexity is another factor that affects the intention toward using mobile payment. Therefore, the adoption of mobile payment rates is faster among those consumers with convenient access to mobiles and other technologies than those who 
do not have the same. Similarly to the perceived usefulness, financial resources also affect the perceived ease of use. It has an inverse relationship; the higher the perceived financial resources, the less intention use (Ooi \& Tan, 2016). This formulates the following two hypotheses.

H6. Perceived usefulness influence an individual's mobile payment intention use and ultimately affects the actual user behavior.

H7. Perceived ease of use influence an individual's mobile payment intention use and ultimately affects the actual user behavior.

Perceived Security Risk: - The feel of a safe environment is essential to adopt any new technology. The user wants to feel that the service is reliable and safe. The private data and financial assets are always on top of customers' minds. Data might be lost or stolen from mobile devices or wrong applications like malware or viruses' malicious software and hacker attacks (Chaouali \& Hedhli, 2019). Therefore, consumers will be more likely to use the mobile payment service if they believe that mobile service providers and retailers are honest, sincere in keeping promises and taking full responsibility in the eventuality of any identity theft, fraud, or security issues (Ooi \& Tan, 2016).

H8. Perceived security risk influence an individual's mobile payment intention use and ultimately affects the actual user behavior.

Attitude: - This can be referred to as the person's feeling regarding whether doing the behavior is favorable or unfavorable (Mostafa, 2020). The positive or negative attitude impacted mainly by the intensity of the behavior and convictions concerning the likelihood of the result (Mostafa, 2020) and (Oertzen \& Odekerken-Schröder, 2019). Many previous studies have considered attitude as a common factor for determining mobile payment adoption. As a result, it drove the researcher to hypothesize that user's attitudes toward mobile payment positively influence (Flavian, 2020). In the context relevant to mobile payment, the more favorable or more robust the attitude toward mobile Payment, the more positive the individual's intention toward undertaking the actual use of Mobile Payment.

H9. Attitude influence an individual's mobile payment intention use and ultimately affects the actual user behavior.

Subjective Norms: - refers to the belief about whether one's social group or significant ones think a person can perform the behavior (Mazambani \& Mutambara, 2019). In short, it is the social factors that affect behavior (Harb et al., 2019). It is related to a person's perception of the behavior's social environment and the perceived pressure from an individual's reference group to perform the target behavior (Mazambani \& Mutambara, 2019). In this study, the subjective norms mean the degree of perceived stress on the respondents from their reference group to the mobile payment's actual use.

H10. Subjective norms influence an individual's mobile payment intention use and ultimately affects the actual user behavior.

Perceived control behavior: - The individual perception of whether he or she has the required resources, skills and opportunities to perform the activity (Mazambani \& Mutambara, 2019). Therefore, the more an individual has the required skills, resources, opportunity, and ease to perform the behavior, the more intention toward the mobile payment behavior.

H11. Perceived control behavior influences an individual's mobile payment intention use and ultimately affects the actual user behavior.

Mobile payment intention use: - Behavioral intention use mediates the relationship between actual use/implementation of technology and the adoption intention (Farah, et al., 2018). Previous researchers reported that technology usage takes off by consumer's behavioral intention and evaluation (Farah, et al., 2018).

H12. Individual's Mobile payment intention use influence actual user behavior.

Experience with Mobile Payment: - The consumer accumulates experience in using mobile payment, which influences the strength of the relation between different variables and intention toward using mobile payment. The ability to use technology is a combination of the experience, training and knowledge that an individual has regarding that technology (Liébana-Cabanillas, et al., 2020). Different bad experiences of individuals like individuals faced issues in returning the item, lost money in the transaction, and reverted a failed transaction, which made these customers more cautious in using mobile Payment (Vashistha, et al., 2019). Therefore, the researcher proposed the moderator impact of the experience, which influence the relation between actual mobile uses. 


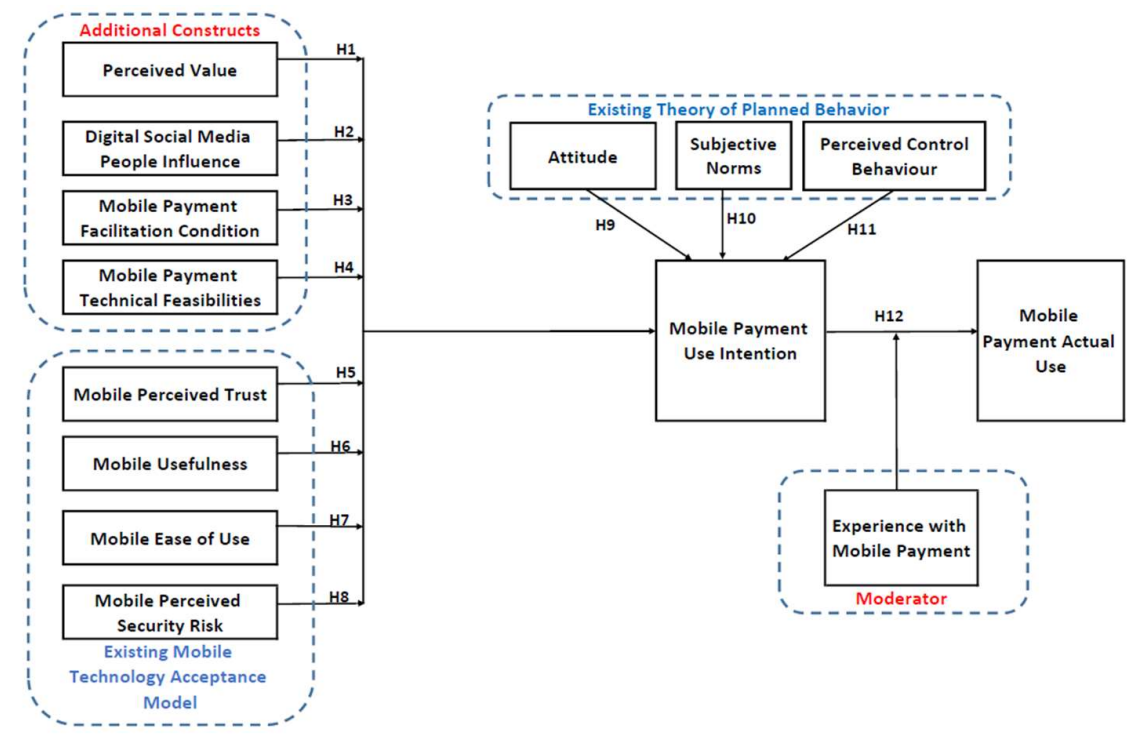

Figure 1

Proposed Revised Mobile Payment Technology Acceptance Model and Behaviour (MPTAMB) and the proposed hypothesis

\section{RESEARCH METHODOLOGY}

The problem addressed in this study is the availability of mobile payment technology. However, the acceptance to form the actual use compared to the other payment channels is very low. The study addresses common issues across the world. The research adopted a mix-methodology. In this method, a designed questionnaire distributed to collect primary data from the study participants. The quantitative data collection to generalize exploratory will identify the outer, followed by qualitative data collection for in-depth explanatory analysis to identify characteristic interpretation (JosephNg , 2018). The target population is the population of ultimate interest. However, because of practicalities, the entire target population often cannot be studied. The study population is a subset of the target population that can be studied. The Sample is the subsets of study populations used in research because not every member of the study population can be measured. Therefore, the target population for this study is public people worldwide.

Among the variety of sampling techniques, Convenience sampling was found more suitable for this research purpose. The leading researcher here will be able to overcome many of the limitations associated with the research. For example, it is possible by this technique to use friends or family as a sample is more accessible, making the respondents available and easy to access. Additionally, the leading researcher works as an e-payment Specialist in the Information technology authority in the sultanate of Oman. Utilizing the connection with all local banks, employees and ministries, and private companies that use the internet payment gateway is possible. By approaching these people in these organizations will be potential for gathering quality data. Therefore, the non-probability convenience sample is the least expensive, least time consuming and the most convenient for this research purpose. Based on official figures of the sultanate of Oman population (National Centre for Statistics and Information, 2020), after excluding the age groups (0-4) and (5-9), the target population is 3727910.

After setting the confidence level at $90 \%$, the calculated sample size is 271 . By adding nine more respondents to accommodate the non-fully responded questionnaire, the total is 280 . This research study's data collection will be by using a constructed questionnaire survey and using google forms as a collection instrument. The questionnaire forms can spread using web tools, emails and social media. The questionnaire adapted Likert scale of 7 ( 1 is "strongly Disagree" to 7, which is "strongly Agree") and open-ended questions. The statistical software used for this study will be the SmartPLS. The 
instruments in the questionnaire of this study are developed based on the review of existing and past literature. This approach will positively affect the instruments' quality and get the benefit of attested instruments reused.

Validity and reliability increase the research transparency and reduce the opportunities to insert bias in the research (Mohajan, 2017). Cronbach's alpha (a); is the most common internal consistency measure (Mohajan, 2017). The variable alpha score above 0.7 is generally considered acceptable. In contrast, the variable that scores less than 0.7 then might have the negative impact that will be investigated (Mohajan, 2017). The pilot phase respondent data has been analyzed using the Smart-PLS v.3.3.3.

\subsection{Pre-test}

At the end, creating the ideal survey questionnaire is unattainable. Researchers, on the other hand, can still design valuable surveys. It is vital to pre-test the survey questionnaire before deploying it to assess its usefulness. Pretesting can help determine the survey's strengths and weaknesses in question type, wording, and sequence. The pre-test importance is to address any potential issues that may arise during data collection. As explained by (Leong, et al., 2021), a pre-test is vital to ensure any ambiguity in question is addressed to ensure understanding of the question by the participants is according to what they are designed and intended. Although this research study aided by past literature's questionnaire instrument, pre-testing can also help ensure employing the instrument to test the desired variables. Therefore, two approaches were employed to pre-test the questionnaire participating and undeclared.

Participating: - the participant is informed of the purpose of the questionnaire to hand over rather than just asking to fill the questionnaire. This approach was facilitated in an interview set by the researcher. During the interview, the participant was asked to explain the reaction to question form, wording, and order of questions. This approach was helpful to determine whether questionnaire instruments are clear and understandable. Four participants were involved in this approach; the first is a Professor of Economics (Associate Dean - Research and Innovation) from Middle East College in the Sultanate of Oman. The second one is a doctorate lecturer in the same university. The other two are expert in the field; the first is a senior employee in the e-channel department in Bank Muscat, and the second is the assistant general manager in Bank al Izz- Sultanate of Oman.

Undeclared: - the participant in this approach was asked to fill the questionnaire without informing the purpose is just a pre-test. It was just like an actual questionnaire given to the participant. The participant is informed that this practice is voluntary, and his/her response will be used only for the study purpose. No names were requested or emails. As we designed the questionnaire in two languages, two participants chose the Arabic version, and the other two chose the English version.

The participating group commented on the sequence of the question and included more instrument to measure the variable, accordingly enhance the sequence and applied the new instrument after evaluating the length of the questionnaire. While the undeclared group suggested some wording in the Arabic version, they suggested arranging the multiple-choice option horizontally to reduce the scrolling down instead of vertically. Most of the questions need to scroll down to see the complete list of the answers. This phase highlighted valuable feedback and commented to enhance the questionnaire before deploying it to the actual study sample.

\subsection{Data collection and respondents demographic profile}

The entire prior distribution of the questionnaire, a sample of 10 university doctors and students, was chosen to conduct a questionnaire trial and error test. Pilot test participants have commented in some of the questionnaires and accordingly evaluated the comments and enhanced. Based on feedback received, four questions were reworded to improve their clarity and understanding. The data in the pilot test were collected using google forms. After that, the questionnaire was uploaded in google forms. The link to the survey was sent via different applications such as (WhatsApp groups, emails, social media platforms to achieve an adequate sample size for the study. The questionnaire content validity went through the pre-test stage. One hundred one respondents received the links and answered the questionnaire list of questions. The demographic profile of respondents is shown in Table 1 Respondants Demographic profile. The respondents were voluntarily answering the questionnaire. The 
first page in the survey to select the preferred language. Then complete information about the purpose of the survey and confidentiality of the data. In general, the respondents are between the age of 15 to 55 years old, which are a potential group of mobile payment applications. $43.5 \%$ of the respondents were graduates (Bachelor degree), 23.7\% postgraduate and above, 13.8 holding diplomas, and 18.8 are high secondary school or less. In terms of using mobile payment applications, $94 \%$ of respondents used mobile payment previously.

Table 1 Respondants Demographic profile

\begin{tabular}{|c|c|c|c|}
\hline Characteristics & Answer & Number & Percentage (\%) \\
\hline \multirow[t]{2}{*}{ Language } & Arabic & 64 & 63.37 \\
\hline & English & 37 & 36.63 \\
\hline \multirow[t]{6}{*}{ Age } & Less Than 15 & 0 & 0.00 \\
\hline & 15 To 25 & 20 & 19.80 \\
\hline & 26 To 35 & 30 & 29.70 \\
\hline & 36 To 45 & 31 & 30.69 \\
\hline & 46 To 55 & 20 & 19.80 \\
\hline & Above 55 & 0 & 0.00 \\
\hline \multirow[t]{4}{*}{ Education Level } & High secondary school or less & 19 & 18.81 \\
\hline & Diploma & 14 & 13.86 \\
\hline & Undergraduate (Bachelor) & 44 & 43.56 \\
\hline & Postgraduate (Master and Above) & 24 & 23.76 \\
\hline \multirow[t]{2}{*}{ Do you use a mobile Payment Application? } & Yes & 6 & 5.94 \\
\hline & No & 95 & 94.06 \\
\hline \multirow{5}{*}{$\begin{array}{l}\text { If yes, since when you started to use mobile } \\
\text { payment }\end{array}$} & Less Than 1 Year & 4 & 3.96 \\
\hline & 1 to 2 years & 31 & 30.69 \\
\hline & 3 to 4 Years & 30 & 29.70 \\
\hline & More than 5 Years & 30 & 29.70 \\
\hline & $\mathrm{N} / \mathrm{A}$ & 6 & 5.94 \\
\hline \multirow{2}{*}{$\begin{array}{l}\text { Have you ever encountered or faced a } \\
\text { problem or issue because of mobile payment? }\end{array}$} & Yes & 76 & 75.25 \\
\hline & No & 25 & 24.75 \\
\hline \multirow{5}{*}{$\begin{array}{l}\text { If yes, would you please let us know what the } \\
\text { nature of the problem you faced is }\end{array}$} & Network Issue & 4 & 3.96 \\
\hline & Login Issue & 31 & 30.69 \\
\hline & Transaction Issue & 3 & 2.97 \\
\hline & Unfamiliar with application & 8 & 7.92 \\
\hline & Other & 55 & 54.46 \\
\hline
\end{tabular}

\subsection{Outer measurement model assessment}

Table 2 Loading Factor, Crobach's Alpha, roh_A, Composite relaibility, AVE showed that all variables in the measurement model ranged from 0.772 to 0.985 for Cronbach's Alpha, rho_A and Composite Reliability above the minimum threshold of 0.077 ( Al-Saedi, et al., 2020). Therefore the internal reliability of consistency is established. The table also reports the factor loading for all the items. All are above the recommended value of 0.07 in calculating the convergent validity. Similarly cross loading for all items were established as per the report showed in Table 3 Discriminant Validity Cross Loadings 
Table 2 Loading Factor, Crobach's Alpha, roh_A, Composite relaibility, AVE Construct Item loadin Cronbach' rho g $\quad$ s Alpha $\quad$ A

\begin{tabular}{|c|c|c|c|c|c|c|}
\hline & & g & s Alpha & & $\begin{array}{l}\text { e } \\
\text { Reliabilit } \\
\text { y }\end{array}$ & $\begin{array}{l}\text { Variance } \\
\text { Extracte } \\
\text { d (AVE) }\end{array}$ \\
\hline \multirow[t]{4}{*}{ Attitude } & AT1 & 0.958 & \multirow[t]{4}{*}{0.979} & \multirow[t]{4}{*}{0.980} & \multirow[t]{4}{*}{0.985} & \multirow[t]{4}{*}{0.941} \\
\hline & AT2 & 0.972 & & & & \\
\hline & AT3 & 0.970 & & & & \\
\hline & AT4 & 0.980 & & & & \\
\hline \multirow{3}{*}{$\begin{array}{l}\text { Mobile Payment Actual Use } \\
\text { Behavior }\end{array}$} & AUB1 & 0.928 & \multirow[t]{3}{*}{0.896} & \multirow[t]{3}{*}{0.948} & \multirow[t]{3}{*}{0.933} & \multirow[t]{3}{*}{0.824} \\
\hline & AUB2 & 0.878 & & & & \\
\hline & AUB3 & 0.917 & & & & \\
\hline \multirow{3}{*}{$\begin{array}{l}\text { Digital Social Media People } \\
\text { Influence }\end{array}$} & DSMPI & 0.916 & \multirow[t]{3}{*}{0.856} & \multirow[t]{3}{*}{0.903} & \multirow[t]{3}{*}{0.932} & \multirow[t]{3}{*}{0.873} \\
\hline & 1 & & & & & \\
\hline & $\begin{array}{l}\text { DSMPI } \\
2\end{array}$ & 0.952 & & & & \\
\hline \multirow[t]{4}{*}{ Facilitating Condition } & FC1 & 0.835 & \multirow[t]{4}{*}{0.938} & \multirow[t]{4}{*}{0.956} & \multirow[t]{4}{*}{0.956} & \multirow[t]{4}{*}{0.845} \\
\hline & FC2 & 0.929 & & & & \\
\hline & FC3 & 0.955 & & & & \\
\hline & FC4 & 0.952 & & & & \\
\hline \multirow[t]{4}{*}{ Mobile Payment Intention Use } & IU1 & 0.952 & \multirow[t]{4}{*}{0.974} & \multirow[t]{4}{*}{0.975} & \multirow[t]{4}{*}{0.981} & \multirow[t]{4}{*}{0.928} \\
\hline & IU2 & 0.958 & & & & \\
\hline & IU3 & 0.972 & & & & \\
\hline & IU4 & 0.972 & & & & \\
\hline Perceived Behavioral Control & PBC1 & 0.961 & 0.960 & 0.960 & 0.974 & 0.926 \\
\hline & PBC2 & 0.963 & & & & \\
\hline & PBC3 & 0.963 & & & & \\
\hline Perceived ease of Use & PEoU1 & 0.922 & 0.958 & 0.963 & 0.969 & 0.888 \\
\hline & PEoU2 & 0.950 & & & & \\
\hline & PEoU3 & 0.957 & & & & \\
\hline & PEoU4 & 0.940 & & & & \\
\hline Perceived Security Risk & PSR1 & 0.869 & 0.772 & 0.822 & 0.896 & 0.811 \\
\hline & PSR2 & 0.931 & & & & \\
\hline Perceived Trust & PT1 & 0.836 & 0.894 & 0.894 & 0.927 & 0.760 \\
\hline & PT2 & 0.837 & & & & \\
\hline & PT3 & 0.902 & & & & \\
\hline & PT4 & 0.908 & & & & \\
\hline Perceived Usefulness & PU1 & 0.840 & 0.950 & 0.966 & 0.964 & 0.871 \\
\hline & PU2 & 0.967 & & & & \\
\hline & PU3 & 0.969 & & & & \\
\hline & PU4 & 0.950 & & & & \\
\hline Perceived Value & PV1 & 0.944 & 0.949 & 0.950 & 0.967 & 0.908 \\
\hline & PV2 & 0.967 & & & & \\
\hline & PV3 & 0.948 & & & & \\
\hline Subjective Norms & SN1 & 0.884 & 0.847 & 0.849 & 0.908 & 0.767 \\
\hline & SN2 & 0.831 & & & & \\
\hline
\end{tabular}




\begin{tabular}{|c|c|c|c|c|c|c|}
\hline & SN3 & 0.911 & & & & \\
\hline \multirow[t]{2}{*}{ Technical Feasibilities } & TF1 & 0.921 & 0.840 & 0.845 & 0.926 & 0.861 \\
\hline & TF2 & 0.935 & & & & \\
\hline
\end{tabular}

Table 3 Discriminant Validity - Cross Loadings

\begin{tabular}{|c|c|c|c|c|c|c|c|c|c|c|c|c|c|}
\hline Item & $\mathbf{A T}$ & MPAUB & DSMPI & FC & MPIU & PCB & PEoU & PSR & PT & $\mathbf{P U}$ & PV & SN & TF \\
\hline AT1 & 0.958 & 0.667 & 0.738 & 0.775 & 0.786 & 0.834 & 0.804 & 0.631 & 0.731 & 0.730 & 0.786 & 0.726 & 0.836 \\
\hline AT2 & 0.972 & 0.672 & 0.676 & 0.829 & 0.822 & 0.907 & 0.899 & 0.713 & 0.687 & 0.853 & 0.822 & 0.780 & 0.891 \\
\hline AT3 & 0.970 & 0.746 & 0.791 & 0.872 & 0.789 & 0.876 & 0.838 & 0.695 & 0.715 & 0.789 & 0.794 & 0.745 & 0.859 \\
\hline AT4 & 0.980 & 0.691 & 0.695 & 0.855 & 0.847 & 0.924 & 0.908 & 0.736 & 0.716 & 0.848 & 0.845 & 0.787 & 0.906 \\
\hline AUB1 & 0.642 & 0.92 & 0.754 & 0.707 & 0.636 & 0.592 & 0.570 & 0.501 & 0.471 & 0.574 & 0.714 & 0.702 & 0.706 \\
\hline AUB2 & 0.520 & 0.878 & 0.694 & 0.653 & 0.536 & 0.508 & 0.454 & 0.579 & 0.467 & 0.449 & 0.649 & 0.627 & 0.558 \\
\hline AUB3 & 0.738 & 0.917 & 0.737 & 0.777 & 0.872 & 0.741 & 0.706 & 0.580 & 0.553 & 0.660 & 0.828 & 0.571 & 0.793 \\
\hline DSMI1 & 0.564 & 0.625 & 0.916 & 0.716 & 0.553 & 0.562 & 0.556 & 0.542 & 0.461 & 0.549 & 0.668 & 0.451 & 0.672 \\
\hline DSMPI2 & 0.801 & 0.849 & 0.952 & 0.870 & 0.727 & 0.789 & 0.713 & 0.634 & 0.567 & 0.712 & 0.859 & 0.636 & 0.846 \\
\hline FC1 & 0.637 & 0.541 & 0.664 & 0.835 & 0.602 & 0.708 & 0.715 & 0.644 & 0.405 & 0.626 & 0.670 & 0.540 & 0.707 \\
\hline FC2 & 0.778 & 0.701 & 0.840 & 0.929 & 0.700 & 0.840 & 0.784 & 0.585 & 0.576 & 0.769 & 0.807 & 0.622 & 0.818 \\
\hline FC3 & 0.839 & 0.801 & 0.821 & 0.955 & 0.855 & 0.851 & 0.819 & 0.777 & 0.585 & 0.757 & 0.923 & 0.696 & 0.915 \\
\hline FC4 & 0.875 & 0.835 & 0.816 & 0.952 & 0.798 & 0.877 & 0.830 & 0.669 & 0.623 & 0.817 & 0.852 & 0.735 & 0.887 \\
\hline IU1 & 0.813 & 0.708 & 0.649 & 0.755 & 0.952 & 0.847 & 0.827 & 0.576 & 0.616 & 0.751 & 0.862 & 0.660 & 0.865 \\
\hline IU2 & 0.756 & 0.771 & 0.630 & 0.761 & 0.958 & 0.802 & 0.790 & 0.775 & 0.610 & 0.714 & 0.834 & 0.656 & 0.798 \\
\hline IU3 & 0.780 & 0.767 & 0.694 & 0.774 & 0.972 & 0.815 & 0.809 & 0.730 & 0.620 & 0.726 & 0.844 & 0.662 & 0.836 \\
\hline IU4 & 0.873 & 0.757 & 0.708 & 0.843 & 0.972 & 0.919 & 0.909 & 0.700 & 0.674 & 0.859 & 0.889 & 0.711 & 0.903 \\
\hline PBC1 & 0.896 & 0.644 & 0.710 & 0.872 & 0.857 & 0.961 & 0.915 & 0.655 & 0.676 & 0.867 & 0.879 & 0.744 & 0.903 \\
\hline PBC2 & 0.846 & 0.681 & 0.736 & 0.851 & 0.829 & 0.963 & 0.881 & 0.686 & 0.684 & 0.864 & 0.823 & 0.701 & 0.847 \\
\hline PBC3 & 0.893 & 0.684 & 0.685 & 0.859 & 0.849 & 0.963 & 0.937 & 0.752 & 0.650 & 0.881 & 0.837 & 0.749 & 0.877 \\
\hline PEoU1 & 0.873 & 0.598 & 0.619 & 0.785 & 0.792 & 0.892 & 0.922 & 0.778 & 0.695 & 0.881 & 0.777 & 0.721 & 0.830 \\
\hline PEoU2 & 0.852 & 0.701 & 0.692 & 0.848 & 0.909 & 0.932 & 0.950 & 0.663 & 0.678 & 0.828 & 0.850 & 0.684 & 0.873 \\
\hline PEoU3 & 0.825 & 0.612 & 0.638 & 0.821 & 0.767 & 0.886 & 0.957 & 0.644 & 0.661 & 0.917 & 0.757 & 0.661 & 0.819 \\
\hline PEoU4 & 0.801 & 0.549 & 0.640 & 0.774 & 0.779 & 0.856 & 0.940 & 0.570 & 0.731 & 0.849 & 0.741 & 0.624 & 0.781 \\
\hline PSR1 & 0.477 & 0.549 & 0.561 & 0.584 & 0.543 & 0.489 & 0.468 & 0.869 & 0.433 & 0.463 & 0.538 & 0.544 & 0.498 \\
\hline PSR2 & 0.774 & 0.554 & 0.584 & 0.719 & 0.736 & 0.779 & 0.763 & 0.931 & 0.752 & 0.688 & 0.693 & 0.647 & 0.719 \\
\hline PT1 & 0.642 & 0.422 & 0.486 & 0.545 & 0.584 & 0.624 & 0.688 & 0.512 & 0.836 & 0.654 & 0.482 & 0.503 & 0.568 \\
\hline PT2 & 0.593 & 0.344 & 0.415 & 0.419 & 0.560 & 0.562 & 0.601 & 0.550 & 0.837 & 0.513 & 0.449 & 0.413 & 0.443 \\
\hline PT3 & 0.691 & 0.596 & 0.580 & 0.600 & 0.589 & 0.632 & 0.631 & 0.701 & 0.902 & 0.600 & 0.618 & 0.758 & 0.629 \\
\hline PT4 & 0.627 & 0.570 & 0.453 & 0.531 & 0.545 & 0.605 & 0.632 & 0.609 & 0.908 & 0.617 & 0.540 & 0.702 & 0.533 \\
\hline PU1 & 0.586 & 0.502 & 0.588 & 0.640 & 0.577 & 0.701 & 0.702 & 0.449 & 0.478 & 0.840 & 0.626 & 0.493 & 0.637 \\
\hline PU2 & 0.793 & 0.634 & 0.674 & 0.776 & 0.759 & 0.882 & 0.893 & 0.632 & 0.676 & 0.967 & 0.771 & 0.612 & 0.799 \\
\hline PU3 & 0.818 & 0.613 & 0.659 & 0.770 & 0.779 & 0.859 & 0.891 & 0.658 & 0.691 & 0.969 & 0.746 & 0.658 & 0.822 \\
\hline PU4 & 0.867 & 0.610 & 0.636 & 0.825 & 0.813 & 0.912 & 0.924 & 0.673 & 0.682 & 0.950 & 0.791 & 0.695 & 0.836 \\
\hline PV1 & 0.771 & 0.781 & 0.775 & 0.830 & 0.824 & 0.815 & 0.759 & 0.608 & 0.567 & 0.724 & 0.944 & 0.666 & 0.863 \\
\hline PV2 & 0.845 & 0.812 & 0.851 & 0.872 & 0.838 & 0.852 & 0.799 & 0.613 & 0.595 & 0.756 & 0.967 & 0.668 & 0.919 \\
\hline PV3 & 0.778 & 0.749 & 0.746 & 0.851 & 0.880 & 0.848 & 0.820 & 0.756 & 0.555 & 0.777 & 0.948 & 0.653 & 0.884 \\
\hline SN1 & 0.688 & 0.568 & 0.477 & 0.600 & 0.643 & 0.690 & 0.655 & 0.466 & 0.577 & 0.608 & 0.602 & 0.884 & 0.637 \\
\hline SN2 & 0.642 & 0.673 & 0.630 & 0.683 & 0.600 & 0.613 & 0.552 & 0.697 & 0.543 & 0.528 & 0.636 & 0.831 & 0.631 \\
\hline SN3 & 0.728 & 0.571 & 0.454 & 0.587 & 0.588 & 0.691 & 0.668 & 0.596 & 0.675 & 0.608 & 0.587 & 0.911 & 0.627 \\
\hline TF1 & 0.751 & 0.626 & 0.692 & 0.748 & 0.778 & 0.788 & 0.733 & 0.544 & 0.494 & 0.685 & 0.840 & 0.617 & 0.921 \\
\hline TF2 & 0.914 & 0.802 & 0.830 & 0.935 & 0.858 & 0.898 & 0.891 & 0.730 & 0.659 & 0.858 & 0.889 & 0.719 & 0.935 \\
\hline
\end{tabular}




\section{FINDING AND DISCUSSION}

This study aimed to examine the influencing factors that affect the intention to use mobile payment and actual use behaviour. This study guided to unfold and understand why people do not use mobile payment.

The new model consists of 12 variables. Mobile Perceived value construct is vital in the proposed model. The quick access, time-saving, loyalty points redemptions and reduction in fees were found relevant to enhance the perceived value of using mobile payment per the interviewed participant respondents. The reliability test indicated that this variable is reliable. The Cronbach's alpha scored 0.949 from this first pilot test of 101 participant's responses.

Digital Social media people influence the user decision on using mobile payment. Respondents indicated that reviewing the online contents and rating of the service providers makes the user more comfortable to use the mobile payment. The indicator shows more weightage on the positive side. The preliminary descriptive analysis reported that around $74 \%$ of the respondent checks the online content and act accordingly. The Cronbach's Alpha reported 0.856, which indicates how reliable this construct is to form the mobile payment's actual use.

Perceiving security on mobile payment, especially on mobile payment systems, exchanging sensitive data like bank card details also influences mobile payment use decisions. Respondents stated that security is an issue. However, if they got assurance from the mobile payment provider, to compensate for account hacking or miss usage of their account caused by the use of the application. The Cronbach test reported the reliability of the construct at 0.772 .

The perceived trust was measured using two instruments (Likert 7 scale). The respondents for trusting that unauthorized people cannot get through their access showed about $67 \%$ trust and reported 0.894 Cronbach's Alpha value. Respondent to complete trust on mobile payment provider about scored $73 \%$ (Strongly Agree 22\%, Agree 44 and Somehow Agree 7\%). This indicates that most respondents have trust in Mobile Payment. The reliability test reports 0.865 on the Cronbach's alpha formula for the trust construct.

Similarly, the subjective norms scored 0.847; perceived usefulness scored 0.950, Technical feasibilities scored 0.840 ; perceiving control behavior scored 0.960 . Intention use scored 0.974 . Attitude scored 0.979 , perceived ease of use scored 0.958 .

Table 4 Cronbach's Alpha summry

\begin{tabular}{lc}
\hline Construct & Cronbach's Alpha \\
\hline Attitude & 0.979 \\
\hline Digital Social Media People Influence & 0.856 \\
\hline Facilitation Condition & 0.938 \\
\hline Mobile Payment Actual Use & 0.896 \\
Behaviour & 0.974 \\
\hline Mobile Payment Intention Use & 0.960 \\
\hline Perceived Behavioral Control & 0.958 \\
\hline Perceived Ease of Use & 0.772 \\
\hline Perceived Security Risk & 0.894 \\
\hline Perceived Trust & 0.950 \\
\hline Perceived Usefulness & 0.949 \\
\hline Perceived Value & 0.847 \\
\hline Subjective Norms & 0.840 \\
\hline Technical Feasibilities & \\
\hline
\end{tabular}




\section{SIGNIFICANCE OF THE STUDY}

The global COVID-19 pandemic, with the caution of preventing physical contact, forced the introduction of some alternative payment methods other than cash. The recently gathered data revealed a rapid and dramatic shift in inhabit (Flavian, 2020), prompting the study to concentrate on payment methods that support contactless. The other relative contribution of the research:-

\subsection{Theoretical contribution}

The Mobile Payment Technology Acceptance Model and Behavior (MPTAMB) is the main contribution of this research paper. It employs the integration of Mobile Technology Acceptance Model (MTAM) and the Theory of Planned Behavior (TPB). The TPB and the newly added variables to build the conceptual framework were never used in conjunction with the MTAM to investigate influential factors to determine the actual use of mobile payment. All previous studies used different theories (UTAUT, Extended UTAUT, TAM, and DoI). MTAM with TPB and the newly added construct never used to examine influential factors toward the actual use of mobile payment. Therefore, this study contribution is vital to understand mobile payment's actual use from consumer behavior and technology acceptance.

\subsection{Managerial contribution}

Mobile Payment facilitates a new way of exchanging money value; the organisation needs to have a 360-degree view of mobile payment factors. Although no direct or significant influence of proposed constructs, knowing its effect will shape mobile payment's strategic decision. Also, bank managers should use the findings of this study to raise public awareness of mobile payment by taking appropriate measures to encourage users to use it. Mobile Payment has emerged as a wireless communication channel that adds value to customers while conducting banking transactions. Today mobile payment considered one of the remarkable modern technologies that provide banking services using smartphones.

Mobile Payment now regarded as one of the most advanced technologies for providing banking services via smartphones. This research will provide national and foreign businesses operating in the region to understand better the factors that affect the use and continue to use mobile payment. Furthermore, this research will assist them in designing effective advertising strategies and advancing their marketing plans.

\subsection{Methodological contribution}

This research's main methodological contribution is the revised Mobile Payment Technology Acceptance Model and Behavior (MPTAMB). For this model, the Mobile Technology Acceptance Model (MTAM) and the theory of planned behavior (TPB) used as the base. Additional constructs and moderators added to examine the mobile payment adoption and actual use. The TPB complemented the mobile payment exposure to look into the actual behavior of mobile payment from accepting the technology and looking from the consumer behavior level. This model contributes a different way into looking of researching mobile payment adoption and use.

The expertise acquired from using problem analysis, interpretive methodology and data collection techniques are other analytical contributions. This knowledge may help future research on the implementation and usage of ICT-related policies at the individual level.

Finally, the applicability of theoretical concepts and theories developed in other contexts is a methodological contribution. Therefore, differences in social and cultural settings and relevance of specific research models and theories established in developed countries to studies in an organizational environment and reusing the same at the individual level where the person voluntarily implements the new technology have been questioned. The successful implementation of these theories in this study leads to examples of human behavior interpretation in mobile application technologies.

In addition, there are limitation in quantitative research methodologies as well in qualitative, 
therefore the current research use mix methodology where the quantitative data will be validated by the qualitative data. This approach will provide in-depth explanation for the researched questions and provide rational justification.

\subsection{Social contribution}

Mobile Payment offers a convenient, effectiveness and cost-saving way of making payment. The adoption of mobile payment influences society, supporting transforming society into cashless (Merhi, Hone, Tarhini, \& Ameen, 2020). This transformation improves society's security level. The individuals will not require carrying cash and being vulnerable to being robbed. Therefore, the diffusion of mobile payment can enhance better safe life. In addition mobile payment

Convenience, simplicity, security, and technology are all features of mobile payment systems. It is evolving alongside people's demand, which mobile payment can provide. Therefore, mobile payment diffusion can reduce the hassle of cash movement and let the mobile device handle the task instead. In terms of simplicity, mobile payment replaces even family-related expenses and donations to special needs people using mobile applications integrated with mobile payment systems that give a more simple way to make the donations. Mobile payment contribution is profoundly touching the social life improvement.

In addition, mobile payment is a way to facilitate mechanism that allows individuals to make payments remotely. This leads that individuals can accomplish many work and tasks quickly and with less effort. Also, people's actions, movements, orientations, financial and governmental dealings, education, shopping, and many other details were related to the technology. That made it easier for them to do so that they would not have done it if the technology did not exist for them. Therefore understanding the challenges that face mobile payment technology can make a change that leads to better social life

\section{CONCLUSION AND FUTURE RESEARCH}

To conclude, this research will examine mobile payment adoption by utilising a newly developed model named "Mobile Payment Technology Acceptance Model and Behaviour". The new revised model is the main contribution of this research paper. Based on the conducted test, the results showed how potential the framework and, therefore, the actual running of the data collection stage is promising to answer the research question. This study examines individual intention and actual use of mobile payment technology using the revised Mobile Payment Technology Acceptance Model and Behaviour. The significance of this research lies in the theoretical, methodical, managerial, and social contributions.

In predicting the actual use of mobile payment, the data analysis reported that perceived security risk, technical feasibilities and perceived value were very important and significant variables. Therefore to provoke the actual use of mobile payment, mobile payment providers required to enhance the given value of the mobile payment, improve the security of mobile payment and finally need to allocate strategies to enhance the technical feasibilities of consumer's.

This study examined the actual use of mobile payment by integrating the Mobile Technology Acceptance Model and The Theory of Planned Behavior. The study was carried out in the Sultanate of Oman. Therefore the results cannot be generalized worldwide and might not reflect mobile payment acceptance and actual user behavior in other countries. Future studies recommended expand the research to other countries and perhaps including moderators that affect mobile payment usages, such as service fees, brand influence, and marketing advertisement.

\section{REFERENCES}

Cao, X. et al., 2018. Understanding mobile payment users' continuance intention: a trust transfer perspective. Internet Research, 28(2), pp. 456-476. 
Chaouali, W. \& Hedhli, K. E., 2019. Toward a contagion-based model of mobile banking adoption. International Journal of Bank Marketing, 37(1), pp. 69-96.

Danyali, A. A., 2018. Factors influencing customers' change of behaviors from online banking to mobile banking in Tejarat Bank, Iran. Journal of Organizational Change Management, 31(6), pp. 1226-1233.

Dimitriadis, S., Kyrezis, N. \& Chalaris, M., 2018. A comparison of two multivariate analysis methods for segmenting users of alternative payment means. International Journal of Bank Marketing, 36(2), pp. 322-335.

Esfahani, S. S. \& Ozturk, A. B., 2019. The influence of individual differences on NFC-based mobile payment adoption in the restaurant industry. Journal of Hospitality and Tourism Technology, 10(2), pp. 219-232.

Farah, M. . F., Hasni, M. J. S. \& Abbas, A. K., 2018. Mobile-banking adoption: empirical evidence from the banking sector in Pakistan. International Journal of Bank Marketing, 36(7), pp. 1386-1413.

Feng, Y., Chen, X. \& Lai, I., 2020. The effects of tourist experiential quality on perceived value and satisfaction with bed and breakfast stays in southwestern China. Journal of Hospitality and Tourism Insights, ahead-of-print(ahead-of-print), pp. ahead-of-print.

Feng, Y., Chen, X. \& Lai, I., 2020. The effects of tourist experiential quality on perceived value and satisfaction with bed and breakfast stays in southwestern China. Journal of Hospitality and Tourism Insights, 4(1), pp. 121-135.

Flavian, C., Guinaliu, M. \& Lu, Y., 2020. Mobile payments adoption - introducing mindfulness to better understand consumer behavior. International Journal of Bank Marketing, 38(7), pp. 1575-1599.

Flavian, C., Guinaliu, M. \& Lu, Y., 2020. Mobile payments adoption - introducing mindfulness to better understand consumer behavior. International Journal of Bank Marketing, 38(7), pp. 1575-1599.

Gbongli, K., Xu, Y. \& Amedj, K. M., 2019. Extended Technology Acceptance Model to Predict MobileBased Money Acceptance and Sustainability: A Multi-Analytical Structural Equation Modeling and Neural Network Approach. Sustainability, 11(13), p. 33.

Gossler, T., Sigala, I. F., Wakolbinger, T. \& Buber, R., 2019. Applying the Delphi method to determine best practices for outsourcing logistics in disaster relief. Journal of Humanitarian Logistics and Supply Chain Management, 9(3), pp. 438-474.

Gupta, K. P., Manrai, . R. \& Goel, U., 2019. Factors influencing adoption of payments banks by Indian customers: extending UTAUT with perceived credibility. Journal of Asia Business Studies, 13(2), pp. 173-195.

Harb, A. A. et al., 2019. Social media as a marketing tool for events. Journal of Hospitality and Tourism Technology, 10(1), pp. 28-44.

Hew, J.-J., Lee, V.-H., Ooi, K.-B. \& Lin, B., 2016. Mobile social commerce: The booster for brand loyalty?. Computers in Human Behavior, Volume 59, pp. 142-154.

Islam, M. S. et al., 2019. Intention to adopt mobile banking in Bangladesh: 136 Int. J. Business Information Systems, Vol. 31, No. 1, 2019. Int. J. Business Information Systems, 31(1), pp. 136-151.

Jiang, Y., Miao, M., Jalees, T. \& Zaman, S. I., 2019. Analysis of the moral mechanism to purchase counterfeit luxury goods: evidence from China. Asia Pacific Journal of Marketing and Logistics, 31(3), pp. 647669.

JosephNg , P., 2018. EaaS Optimization: Available yet hidden information technology infrastructure inside medium size enterprise. Technological Forecasting \& Social Change, Volume 132, pp. 165-173. 
Kalinić, Z., Liébana-Cabanillas, F. J., Muñoz-Leiva, F. \& Marinković, V., 2019. The moderating impact of gender on the acceptance of peer-to-peer mobile payment systems. International Journal of Bank Marketing, 38(1), pp. 138-158.

Kang, J., 2018. Mobile payment in Fintech environment: trends, security challenges, and services. HumanCentric Computing and Information Aciences, 8(32).

Khoi, N. H., Tuu, H. H. \& Olsen, S. O., 2018. The role of perceived values in explaining Vietnamese consumers' attitude and intention to adopt mobile commerce. Asia Pacific Journal of Marketing and Logistics, 30(4), pp. 1112-1134.

Kumar, V. et al., 2020. A structural analysis approach to identify technology innovation and evolution path: a case of m-payment technology ecosystem. Journal of Knowledge Management, ahead-of-print(aheadof-print), pp. ahead-of-print.

Leong, C.-M., Tan, K.-L., Puah, C.-H. \& Chong, S.-M., 2020. Predicting mobile network operators users mpayment intention. European Business Review, ahead-of-print(ahead-of-print), pp. ahead-of-print.

Leong, C.-M., Tan, K.-L., Puah, C.-H. \& Chong, S.-M., 2021. Predicting mobile network operators users mpayment intention. European Business Review, 33(1), pp. 104-126.

Letić , J., 2020. Mobile banking statistics: The future of money is in the palm of your hand. [Online] Available at:

[Accessed 19 October 2020].

Liébana-Cabanillas, F., García-Maroto, I., Muñoz-Leiva, F. \& Ramos-de-Luna, I., 2020. Mobile Payment Adoption in the Age of Digital Transformation: The Case of Apple Pay. sustainability, 12(13).

Lin, K.-Y., Wang, . Y.-T. \& Huang, T. K., 2020. Exploring the antecedents of mobile payment service usage: Perspectives based on cost-benefit theory, perceived value, and social influences. Online Information Review, 44(1), pp. 299-318.

Luna, I. R. d., Liébana-Cabanillas, F., Sánchez-Fernández, J. \& Muñoz-Leiva, F., 2018. Mobile payment is not all the same: The adoption of mobile payment systems depending on the technology applied. Technological Forecasting and Social Change, Volume 146, pp. 931-944.

Malik, A., 2018. The main driver of social unsustainability and its remedy. International Journal of Social Economics, 45(6), pp. 973-988.

Mazambani, L. \& Mutambara, E., 2019. Predicting FinTech innovation adoption in South Africa: the case of cryptocurrency. African Journal of Economic and Management Studies, 11(1), pp. 30-50.

Merhi, M., Hone, K., Tarhini, A. \& Ameen, N., 2020. An empirical examination of the moderating role of age and gender in consumer mobile banking use: a cross-national, quantitative study. Journal of Enterprise Information Management, ahead-of-print(ahead-of-print), pp. ahead-of-print.

Mohajan, H., 2017. Two Criteria for Good Measurements in Research: Validity and Reliability. Annals of Spiru Haret University, 3(58-82), p. 32.

Mostafa, R. B., 2020. Mobile banking service quality: a new avenue for customer value co-creation. International Journal of Bank Marketing, 38(5), pp. 1107-1132.

Mouakket, S., 2020. Investigating the role of mobile payment quality characteristics in the United Arab Emirates: implications for emerging economies. International Journal of Bank Marketing, ahead-ofprint(ahead-of-print), pp. ahead-of-print.

Naicker, V. \& Merwe, D. B. V. D., 2018. Managers' perception of mobile technology adoption in the Life Insurance industry. Information Technology \& People, 31(2), pp. 507-526. 
Naith, Q. \& Ciravegna, F., 2020. Definitive guidelines toward effective mobile devices crowdtesting methodology. International Journal of Crowd Science, 4(2), pp. 209-228.

National Centre for Statistics and Information, 2020. Population, Muscat: 2020.

Odoom, R. \& Kosiba, J. P., 2020. Mobile money usage and continuance intention among micro enterprises in an emerging market - the mediating role of agent credibility. Journal of Systems and Information Technology, 22(1), pp. 97-117.

Oertzen, A.-S. \& Odekerken-Schröder, G., 2019. Achieving continued usage in online banking: a postadoption study. International Journal of Bank Marketing, 37(6), pp. 1394-1418.

Ooi, K.-B. \& Tan, G. W.-H., 2016. Mobile technology acceptance model: An investigation using mobile users to explore smartphone credit card. Expert Systems With Applications, Volume 59, pp. 33-46.

Patsiotis, A., Atik, M. \& Perrea, T., 2020. The influence of m-marketing tools on consumer buying process: evidence from the dining sector. International Journal of Retail and Distribution Management, 48(10), pp. 1037-1056.

Patten, E., Ozuem, W. \& Howell, K., 2020. Service quality in multichannel fashion retailing: an exploratory study. Information Technology \& People, 33(4), pp. 1327-1356..

Queirós, A., Faria, D. \& Almeida, F., 2017. Strengths and limitations of qualitative and quantitative research methods. European Journal of Education Studies, 3(9).

Ryu, H.-S., 2018. What makes users willing or hesitant to use Fintech?: the moderating effect of user type. Industrial Management \& Data Systems, 118(3), pp. 541-569.

Semerikova, E., 2020. Payment instruments choice of Russian consumers: reasons and pain points. Journal of Enterprising Communities: People and Places in the Global Economy, 14(1), pp. 22-41.

Simon-kucher \& Partners, 2018. How behavioral science can unleash digital payments adoption, s.1.: s.n.

Song, S. \& Sun, J., 2018. Exploring effective work unit knowledge management (KM): roles of network, task, and KM strategies. Journalof knowledgemanagement, 22(7), pp. 1614-1636.

Tarhini, A., Tarhini, J. \& Tarhini, A., 2019. Information technology adoption and implementation in higher education Evidence from a case study in Lebanon. International Journal of Educational Management, 33(7), pp. 1466-1482.

Trinh, H. . N., Tran, H. H. \& Vuong, D. . H. Q., 2020. Determinants of consumers' intention to use credit card: a perspective of multifaceted perceived risk. Asian Journal of Economics and Banking, ahead-ofprint(ahead-of-print), pp. ahead-of-print.

Tsohou, A. et al., 2020. Privacy, security, legal and technology acceptance elicited and consolidated requirements for a GDPR compliance platform. Information \& Computer Security, 28(4), pp. 531-553.

Vanthomme, S., 2020. 12 Global Payment Statistics Impacting Small \& Mid-size Businesses. [Online] Available at: https://www.ccv.eu/2020/12-global-payment-statistics-impacting-small-mid-sizebusinesses/

[Accessed 19 October 2020].

Vapulus, 2019. Global Online payment statistics $2019 . \quad$ [Online] Available at: https:/www.vapulus.com/en/online-payment-statistics-2019/

[Accessed 19 October 2020].

Vashistha, A., Anderson, R. \& Mare, S., 2019. Examining the use and non-use of mobile payment systems for merchant payments in India. s.1., Association for Computing Machinery, Inc. 
Verma, S., Chaurasia, S. S. \& Bhattacharyya, S. S., 2020. The effect of government regulations on continuance intention of in-store proximity mobile payment services. International Journal of Bank Marketing, 38(1), pp. 34-62.

Wang, Y.-Y., Wang, Y.-S. \& Lin, T.-. C., 2018. Developing and validating a technology upgrade model. International Journal of Information Management, 38(1), pp. 7-26.

Zhao, H., Anong, S. T. \& Zhang, L., 2019. Understanding the impact of financial incentives on NFC mobile payment adoption An experimental analysis. International Journal of Bank Marketing, 37(5), pp. 12961312. 